\title{
Labeling and Patient Knowledge of Dispensed Drugs as Patient Care Indicators in Adulala Health Center Outpatient Pharmacy, Adulala, Ethiopia
}

\author{
Bikila Midaksa, Fanta Gashe, Messay Wolde-Mariam Anshebo, Raghavendra Yarlagadda ${ }^{*}$ \\ College of Public Health and Medical Sciences, Department of Pharmacy, Jimma University, Jimma, Ethiopia.
}

\begin{tabular}{l}
\hline ARTICLE INFO \\
\hline Article history: \\
Received on: 08/05/2015 \\
Revised on: $26 / 06 / 2015$ \\
Accepted on: $15 / 07 / 2015$ \\
Available online: $27 / 09 / 2015$ \\
\hline Key words: \\
Labeling, Dispensed Drugs, \\
Patient Care Indicators, East \\
Shoa, Ethiopia.
\end{tabular}

\begin{abstract}
Background: labeling and knowledge of dispensing drug is important for the patient to identify the contents and to ensure that they have clear and concise information about the use of the dispensed drug. Lack of this may lead the patient to incorrect use, which in turn results in an adverse effect. So the present was undertaken to assess the labeling and patient knowledge of dispensing drugs in Adulala Health Center outpatient pharmacy, Adulala, East Shoa, Ethiopia.

Method: A cross sectional, prospective study was done by examining previously prepared a checklist to gather information from each package of dispensing drugs to patients and exit interview done with patients to assess their knowledge of the dispensed drug at Adulala Health Center Outpatient Pharmacy from January 23 to February 7, 2014. The data were analyzed by using statistical software package SPSS 16.0.

Results: A total of 302 patients was studied of which majority (62.6\%) of them were females and $38.2 \%$ of the patients were in the age group of 21-45. All the patients were aware of the dose and a majority (79.06\%) of them about frequency. The labeling pattern of dispensing drugs attributes $100 \%$ in case of name, strength and expiry of the drug. Patient name was written in only $4.7 \%$ of the dispensed drugs. Out of a total 554 dispensed drugs most $(46.93 \%)$ of them were dispensed for chemotherapeutic to a majority (192) of the patients of 21-45 age groups. Sex has no association with patient knowledge on dosage, frequency, and duration ( $\mathrm{p}$-value $=0.423,0.630,0.115$ ) respectively.

Conclusion: The study depicts that dispensed drugs had poor labeling. Educational level and patient age have a strong association with patient knowledge of dispensing drugs whereas sex has no association with patient knowledge. Dispensing time was short. Not all prescribed medications are dispensed.
\end{abstract}

\section{INTRODUCTION}

Dispensing of drugs is the process of preparing and handing over medicine to a patient on the basis of the prescription which emphasizes more on accurate preparation and labeling of medicine. Any error in the dispensing process can affect the care of the patient (Bonnstra et al., 2003). The label on a dispensed drug will be useful for the patient to identify the contents of the container and the patients get clear information about the use of the drug. Every label on a dispensed drugs should clearly indicate the name, strength, and dosage form of the preparation, the name and address of the pharmacy, the

\footnotetext{
* Corresponding Author

Raghavendra Yarlagadda, College of Public Health and Medical Sciences, Department of Pharmacy, Jimma University. Jimma, Ethiopia Email: raghavendray@gmail.com
}

patient for whom it has been prescribed, storage condition and shelf life of the drug, date of supply gives the patient clear and complete instruction on how and when to take the drug (DACA., 2007). Simplest form of patient education is counseling at the time of dispensing the prescribed drug. At minimum patients should know how to take their medicine, how often, what to do if a dose is missed, and what side effects to watch for and how to store the medication. In Ethiopia, it is commonly noticed that the dispensed drugs were found to be without a label, incomplete label, or illegible labels (Remington., 2005). According to a study done in Iran, prescription of antibiotics and injectable drugs was very high (Cheragali et al., 2004). A study conducted on rational drug use in nine health centers (HCs) and nine health stations (HSS) in North West Ethiopia, the average consultation time in minutes in HSS and HCs was 5.1 and 5.8 respectively, while the dispensing times were 1.5 and 1.9 minutes, respectively (Desta et al., 2006). 
A study done by using WHO's prescribing, patient care and health facility indicators in selected health centers in South West Ethiopia in shebe HC, Yebu HC, Serbo HC and Jimma HC showed that; the mean consultation time spent between the prescriber and patient were 6.50 minutes which was the longest at SHHC and 5.47 minutes which was the shortest time spent at YHC. In this study, the average consultation and dispensing time in health centers was 6.14 minutes and 1.28 minutes (Mulugeta et al., 2011). However; this result was more different than the study in Niger which was 5.75 minutes and 3.25 minutes on average (Mallet et al., 2001). The probable reason for this variation in dispensing time may be due to manpower, set up with dispensary area and ease of access for essential materials like drugs, medical equipment among health centers.

Even though there are different health institutions which are dispensing prescribed drugs, so far, there was no such type of study undertaken in Adulala Health Center outpatient pharmacy. So, the purpose of this study is to asses labeling and patient knowledge of dispensed drugs as a patient care indicator in Adulala Health Center outpatient pharmacy, Adulala, East shoa, Oromiya Region.

\section{METHODS AND MATERIALS}

\section{Study area and period}

Adulala is located 33 kilometers to the South of Bishoftu. The study was conducted from January 23 to February 7, 2014 on patients coming out of outpatient pharmacy of the Adulala Health Center, which located in Liban Chukala, East Shoa, Oromiya region. The patients included were from various health service departments like Outpatient department, Surgery (minor), Internal medicine, Gynecology and Obstetrics, Ophthalmology, Laboratory and Pharmacy.

\section{Study design}

A cross sectional, prospective study was conducted to assess the labeling pattern and patient knowledge of dispensing drugs in patients who were taking their dispensed drugs during normal working hours of the Adulala Health Center. Information from each drug package dispensed to the patient was examined using a pre prepared check list. In addition, to evaluate the individual package, an exit interview was made with patients to assess their understanding of the information provided on the dispensed drugs. The quality of drug labeling was assessed by calculating a mean labeling score composed of seven dispensing attributes. The mean patient knowledge score was also attained by calculating scores composed of four attributes. Dispensing time was recorded for each patient using a stop watch from the entrance to exit of the patient from the pharmacy.

\section{Study population}

All patients with dispensed drugs coming out of Adulala Health Center Outpatient pharmacy during the study period. Patients undergoing Direct Observed Treatment (DOT) of tuberculosis and patients on Antiretroviral Therapy (ART) were excluded from the study. In addition, patients under the age of 6 years and those having hearing impairments are excluded. All patients who got the prescribed drugs and all of their drugs were included during the study period. The convenient sampling technique was used, since the study attempted to cover all consecutive patients who attend the pharmacy to get the prescribed drugs over the study period. The check list was checked for having all the necessary information and whether it was properly filled.

\section{Data collection, data analysis and presentation}

To avoid dispenser bias, interview with the patients was conducted by standing 5 meters away from the dispensing unit and the whole data collection process was done in the midday. Test for statistical association had been employed to see the association of independent and dependent variables. Data was analyzed using statistical software package SPSS version 16.0 and presented using tables. A chi-square test was used to compare if there is an association between the independent variables (age, sex and educational status) and dependent variables (knowledge on dose, duration of treatment, reason for prescription and frequency of use). A P value of 0 to 0.05 was used to compare the association of the variables in the statistical analysis used. When the $P$ value is less than 0.05 there is an association between the variables and when it is greater than 0.05 there is no association. The quality of labeling had been measured and recorded by assigning a score to each of the seven standard dispensing quality attributes, name of the patient, name of the drug, strength of drug, dosage forms, frequency of administration, duration of treatment and expiry date. Correct labeling had been given a score of 1 per attribute and a score of 0 had been given for incorrect or no labeling.

\section{Calculation of indicators}

Percentage of drugs dispensed is calculated by dividing the number of drugs dispensed to a total number of drugs prescribed, then multiplied by 100 (one hundred). Average number of drugs per encounter is calculated by dividing the total number of different drug products to a total number of encounters surveyed. Percentage of patients who adequately recall the dosage schedule was calculated by dividing the number of patients who adequately report dosage schedule for all drugs to a total number of patients interviewed then multiplied by 100 (one hundred). Similar percentage calculation pattern was carried out for frequency of drug, duration of treatment, recalling the frequency of drug and adequate labeling of the drug. Average dispensing time is calculated by dividing the total time for dispensing time to a series of patients to a total number of encounters.

\section{Ethical Consideration}

Consent was obtained from the Adulala Health Center to carry out the research work in the health facility. The purpose of the study was explained to the study subjects and verbal consent was obtained before the interview. Any misunderstanding from the patient side was corrected. The respondents were convinced to tell 
accurate information from the data included in the questionnaire. The patient's identity was maintained confidentially throughout the study period. As the research has minimal risk involved the ethics committee allowed us to take verbal consent and the script of the verbal consent was used to take the consent of the respondents.

\section{RESULTS}

\section{Socio-demographic characteristics of the patients}

A total of 302 patients from outpatient pharmacy were considered in the present study of which the majority $189(62.6 \%)$ were females and $38.1 \%$ of the patients were in the age group of 21-45. The majority of the respondents were in the age groups of $21-45$ years $(38.1 \%)$ followed by $6-10(28.8 \%)$ years and $10-20$ $(21.5 \%)$ years. Educational status of the respondents was found to be very high as most of them were illiterates (71.2\%) out of which $45 \%$ were females (Table 1 ).

Table 1: Background information of patients visited Adulala Health Center Outpatient Pharmacy from January 23- February 7, 2014.

\begin{tabular}{llll}
\hline Background information & $\begin{array}{c}\text { Number of } \\
\text { patients served }\end{array}$ & $\begin{array}{c}\text { Percentage } \\
(\boldsymbol{\%})\end{array}$ \\
\hline Sex & Male & 113 & 37.4 \\
& Female & 189 & 62.6 \\
& Total & 302 & 100 \\
\hline Age in year & $6-10$ & 87 & 28.8 \\
& $10-20$ & 65 & 21.5 \\
& $21-45$ & 115 & 38.1 \\
& $45-55$ & 20 & 6.6 \\
& $>55$ & 15 & 5 \\
& Total & 302 & 100 \\
\hline sducational & Illiterate & 215 & 71.2 \\
& Primary school & 65 & 20.5 \\
& High school & 13 & 4.3 \\
& Diploma and above & 12 & 4 \\
& Total & 302 & 100 \\
\hline
\end{tabular}

\section{Patient knowledge}

All the patients were aware of the dose and a majority $(79.06 \%)$ of them about frequency. Whereas, knowledge on duration of treatment was $204(36.82 \%)$ and reason for prescribing was very low 166 (29.96\%). Patient knowledge score was calculated for each of the four attributes and the mean patient knowledge score was found to be 2.46 which is $(61.46 \%)$ of the total score (Table 2).

Table 2: Patient knowledge on dispensed drugs at Adulala Health Center Outpatient Pharmacy from January 23-February 7, 2014.

\begin{tabular}{llll}
\hline Indicators & \multicolumn{2}{l}{ Drugs dispensed } & Percentage (\%) \\
\hline Dose & Yes & 554 & 100 \\
& No & 0 & 0 \\
& Total & 554 & 100 \\
\hline Frequency & Yes & 438 & 79.06 \\
& No & 116 & 20.94 \\
& Total & 554 & 100 \\
\hline Duration & Yes & 204 & 36.82 \\
& No & 350 & 63.18 \\
& Total & 554 & 100 \\
\hline Reason & Yes & 166 & 29.96 \\
& No & 388 & 70.04 \\
& Total & 554 & 100 \\
\hline
\end{tabular}

\section{Labeling pattern of dispensed drugs}

The labeling pattern of dispensed drugs attributes $100 \%$ in case of name, strength and expiry date of the drug. Patient name was written in only $4.7 \%$ of the dispensed drugs. The mean labeling score in the health center was 4.41 and represents $63.00 \%$ of the total scores. Accordingly, the percentage of the drug adequately labeled was $4.69 \%$ (Table 3).

Table 3: Labeling pattern of dispensed drugs at Adulala Health Center Outpatient Pharmacy from January 23- February 7, 2014.

\begin{tabular}{llll}
\hline Indicators & Drugs dispensed & Percentage (\%) \\
\hline Name of drug & Yes & 554 & 100 \\
& No & 0 & 0 \\
& Total & 554 & 100 \\
\hline Patient name & Yes & 26 & 4.7 \\
& No & 528 & 95.3 \\
& Total & 554 & 100 \\
\hline Strength of the drug & Yes & 554 & 100 \\
& No & 0 & 0 \\
& Total & 554 & 100 \\
\hline Frequency of administration & Yes & 187 & 33.75 \\
& No & 367 & 56.25 \\
& Total & 554 & 100 \\
\hline Dose labeled & Yes & 410 & 74 \\
& No & 144 & 26 \\
& Total & 554 & 100 \\
\hline Duration of treatment & Yes & 159 & 28.7 \\
& No & 395 & 71.3 \\
& Total & 554 & 100 \\
\hline Expiry date & Yes & 554 & 100 \\
& No & 0 & 0 \\
& Total & 554 & 100 \\
\hline
\end{tabular}

\section{Prescribed and dispensed drugs}

Out of a total 554 dispensed drugs most (46.93\%) of them were dispensed for chemotherapeutic followed by Analgesics $(28.34 \%)$ (Table 4)

Table 4: Class of drugs dispensed to patients at Adulala Health Center Outpatient Pharmacy from January 23- February 7, 2014.

\begin{tabular}{lcc}
\hline Class of drugs & $\begin{array}{c}\text { Number of drugs } \\
\text { dispensed }\end{array}$ & $\begin{array}{c}\text { Percentage } \\
(\boldsymbol{\%})\end{array}$ \\
\hline Chemotherapeutic & 260 & 46.93 \\
Analgesics & 157 & 28.34 \\
CNS & 2 & 0.36 \\
GIT & 33 & 5.96 \\
Minerals \& vitamins & 102 & 18.41 \\
Total & 554 & 100 \\
\hline
\end{tabular}

Class of medications dispensed in a different patient age group Out of 554 dispensed drugs Analgesics, GIT, CNS and Mineral and Vitamins were the different class of drugs. From 266 chemotherapeutics $82,59,89,16,14$ were dispensed in the age group of $6-10,10-20,21-45,45-55$ and $>55$ years old respectively which accounts more of all the dispensed class of drugs.

From a total of 157 analgesics 51, 36, 45, 14, 11 were dispensed in age group of 6-10, 10-20, 21-45, $45-55$ and $>55$ years old respectively. From GIT drugs 3, 7, 10, 6, 7 was dispensed in age group of 6-10, 10-20, 21-45, 45-55 and >55 years old 
respectively. From 102 mineral and vitamins 28, 21, 46, 4, 3 were dispensed in age group of 6-10, 10-20, 21-45, 45-55 and >55 years old respectively. And only two CNS drugs were dispensed in the age group of 21- 45 (Table 5).

Table 5: Number of different medications dispensed in each patient age group at Adulala Health Center Outpatient Pharmacy from January 23- February 7, 2014.

\begin{tabular}{lrrrrrr}
\hline Medication & \multicolumn{3}{c}{ Age } & & Total \\
\cline { 2 - 6 } & $6-10$ & $10-20$ & $21-45$ & $45-55$ & $>55$ & \\
\hline Chemotherapeutic & 82 & 59 & 89 & 16 & 14 & 260 \\
Analgesics & 51 & 36 & 45 & 14 & 11 & 157 \\
GIT & 3 & 7 & 10 & 6 & 7 & 33 \\
CNS & 0 & 0 & 2 & 0 & 0 & 2 \\
Mineral and vitamins & 28 & 21 & 46 & 4 & 3 & 102 \\
$\quad$ Total & 164 & 123 & 192 & 40 & 35 & 554 \\
\hline
\end{tabular}

\section{Patient knowledge on dispensed drugs and sex}

Out of a total 554 dispensed drugs most (46.93\%) of them were dispensed for chemotherapeutics to a majority (192) of the patients of 21-45 age groups. All patients, including females and males recalled the dose of drug dispensed to them. From 554 dispensed drugs frequency was recalled in 141 and 246 drugs, duration recalled in 84 and 120, reason for prescription recalled in 91 and 88 by males and females respectively. As chi-square calculation indicates there is no association between the sex of patients and their knowledge (dose, frequency and duration of treatment) on dispensed drugs (Table 6).

Table 6: Patient knowledge on dispensed drugs and sex at Adulala Health Center Outpatient Pharmacy from January 23- February 7, 2014.

\begin{tabular}{llllll}
\hline \multirow{2}{*}{ Knowledge } & \multicolumn{3}{c}{ Sex } & & \\
\cline { 3 - 4 } & & Male & Female & Total & P-value \\
\hline Dose & Know & 206 & 348 & 554 & 0.423 \\
& Doesn't know & 0 & 0 & 0 & \\
& Total & 206 & 348 & 554 & \\
\hline Frequency & Know & 141 & 246 & 387 & 0.630 \\
& Doesn't know & 65 & 102 & 167 & \\
& Total & 206 & 348 & 554 & \\
\hline Duration & Know & 84 & 120 & 204 & 0.115 \\
& Doesn't know & 122 & 228 & 350 & \\
& Total & 206 & 348 & 554 & \\
\hline Reason & Know & 91 & 88 & 179 & 0.000 \\
& Doesn't know & 115 & 260 & 375 & \\
& Total & 206 & 348 & 554 & \\
\hline
\end{tabular}

\section{Patient knowledge on dispensed drugs and age group}

All patients recalled dose of all of drugs dispensed to them. From 554 dispensed drugs frequency was recalled in 107, 91, 141, 27 and 23 drugs, duration recalled in 44, 45, 80, 17 and 12 , reason for prescription recalled in50, 27, 62, 13 and 15 in the age group of 6-10, 10-20, 21-45, 45-55 and >55 years old respectively. As chi-square calculation indicates there is a significant association between age of patients and their knowledge on dispensed drugs (Table 7).
Patient knowledge on dispensed drug and educational status

All patients in all educational status recalled the dose each drug. From 554 dispensed drugs frequency was recalled in 19, 28, 232 and 110 drugs, duration recalled in 17, 7, 134 and 47, reason for prescription recalled in 16, 4, 123 and 41 by Diploma and above, High school, Illiterate and primary school respectively. As chi-square calculation indicates there is a significant association between educational status of patients and knowledge on their dispensed drugs (Table 9). The average dispensing time at the Adulala outpatient pharmacy was found to be 152 second. The minimum and maximum dispensing time were 25 seconds and 420 seconds respectively (Table 9). Due to lack of knowledge and information about the dispensed drug used by the patients it leads to incorrect use, which results in loss of efficacy or occurrence of adverse effects (Remington., 2005). The quality of labeling applied by dispensers, the time spent informing the patients, and the communication skill of the dispensers can therefore affect compliance rates (Bonnstra et al., 2003). In a study done in Burkina Faso eighty-eight percent of the prescribed drugs were on the essential drug list (Kralsce et al., 1999). In the present study a total of 302 patients from outpatient pharmacy were included. Out of 302 patients, the majority 189 (62.6\%) were females. Concerning the age of the respondents, the majority of the respondents were in the age groups of 6-10 (28.8\%) years, 10-20 $(21.5 \%)$ years and $21-45$ years $(38.1 \%)$. Regarding the educational status of the respondents most of them were illiterates $(71.2 \%)$. For 302 patients $554(84.58 \%)$ were actually dispensed out of the total drugs prescribed, which was lower than the study done in Niger (100\%), North West Ethiopia (89\%) (Mallet et al., 2001; Desta et al., 2006), and a study done at Yebu Health center (89.04\%), Serbo Health Center $(89.55 \%)$, whereas greater than the study done at Shebe health center $(77.74 \%)$ and Jimma health center $(77.77 \%)$, India $(54.7 \%)$, South East Asia (43\%) (Nismbase., 2006; Mallet et al., 2001; Mulugeta et al., 2011; Goplakrishnan et al., 2012). The average number of drugs per encounter was found to be 1.83 which is even less than the national value (1.99) and also the study done at Shebe health center (2.88) (MOH., 2003; Mulugeta et al 2011). This indicates that there are no poly pharmacy problem and it could also be the reason for good patient knowledge of dispensed drugs though dispensing time was short. The label on dispensed drugs uniquely identifies the content of container and ensures that the patient gets clear and concise information about the use of drugs. In this study all the dispensed drugs were labeled with their name, strength and expiry date even though it was not labeled by the pharmacist, but which already was on the original package of the drug and also it was not in the language all patients can understand. In addition It was observed that the majority of dispensed drugs were dispensed in their genuine original packages and the rest were dispensed in different envelops and plastic containers. All 554 (100\%) dispensed drugs were labeled with their name, strength and expiry date. This value is greater than the study in Botswana which is $50 \%$ (Bonnstra et al., 2003). The reason for this variation in percentage was due to the fact that most of the drugs such as 
Table 7: Patient knowledge on dispensed drugs and age group at Adulala Health Center Outpatient Pharmacy from January 23- February 7, 2014.

\begin{tabular}{|c|c|c|c|c|c|c|c|c|}
\hline \multicolumn{2}{|c|}{ Knowledge on dispensed drug } & \multicolumn{6}{|c|}{ Age group } & \multirow[t]{2}{*}{ P-value } \\
\hline & & $6-10$ & $10-20$ & $21-45$ & $45-55$ & $>55$ & Total & \\
\hline \multirow[t]{3}{*}{ Dose } & Know & 156 & 124 & 199 & 49 & 26 & 554 & 0.000 \\
\hline & Doesn't know & 0 & 0 & 0 & 0 & 0 & 0 & \\
\hline & Total & 156 & 124 & 199 & 49 & 26 & 554 & \\
\hline \multirow[t]{3}{*}{ Frequency } & Know & 107 & 91 & 141 & 27 & 23 & 389 & 0.034 \\
\hline & Doesn't know & 49 & 35 & 58 & 22 & 8 & 165 & \\
\hline & Total & 156 & 126 & 199 & 46 & 31 & 554 & \\
\hline \multirow[t]{3}{*}{ Duration } & Know & 44 & 45 & 80 & 17 & 12 & 198 & 0.000 \\
\hline & Doesn't know & 112 & 79 & 109 & 32 & 16 & 356 & \\
\hline & Total & 156 & 124 & 199 & 49 & 26 & 554 & \\
\hline \multirow[t]{3}{*}{ Reason } & Know & 50 & 27 & 62 & 13 & 15 & 167 & 0.000 \\
\hline & Doesn't know & 106 & 97 & 137 & 36 & 13 & 387 & \\
\hline & Total & 156 & 124 & 199 & 49 & 28 & 554 & \\
\hline
\end{tabular}

Table 8: Patient knowledge on dispensed drug and educational status at Adulala Health Center Outpatient Pharmacy from January 23 - February 7, 2014.

\begin{tabular}{|c|c|c|c|c|c|c|c|}
\hline \multicolumn{2}{|c|}{ Knowledge on dispensed drugs } & \multicolumn{5}{|l|}{ Educational status } & \multirow[b]{2}{*}{ p-value } \\
\hline & & Diploma and above & High school & Illiterate & Primary school & Total & \\
\hline \multirow[t]{3}{*}{ Dose } & Know & 20 & 31 & 374 & 129 & 554 & 0.000 \\
\hline & Doesn't know & 0 & 0 & 0 & 0 & 0 & \\
\hline & Total & 20 & 31 & 374 & 129 & 554 & \\
\hline \multirow[t]{3}{*}{ Frequency } & Know & 19 & 28 & 232 & 110 & 390 & 0.000 \\
\hline & Doesn't know & 1 & 3 & 142 & 19 & 184 & \\
\hline & Total & 20 & 31 & 374 & 129 & 554 & \\
\hline \multirow[t]{3}{*}{ Duration } & Know & 17 & 7 & 134 & 47 & 207 & 0.000 \\
\hline & Doesn't know & 3 & 24 & 240 & 82 & 350 & \\
\hline & Total & 20 & 31 & 374 & 129 & 554 & \\
\hline \multirow[t]{3}{*}{ Reason } & Know & 16 & 4 & 123 & 41 & 184 & 0.000 \\
\hline & Doesn't know & 4 & 27 & 251 & 88 & 370 & \\
\hline & Total & 20 & 31 & 374 & 129 & 554 & \\
\hline
\end{tabular}

tablets, drugs in ampoules and bottles were dispensed in their original package labeled with their strength, name and expiry date and since it was labeled in English it could be difficult for the patients to understand. Only $26(4.7 \%)$ of them were labeled with patient name and if the name of patient was not indicated on label, medication error may occur since the drug may be used unknowingly by other members of the family of patient. The percentage $26(4.7 \%)$ of dose labeled adequately of dispensed drugs was very low than the study done at Shebe Health Center (71.4\%), Yebu Health Center (73.33\%), Serbo Health Center (67.27\%), Jimma Health Center (68.33\%) and Ghana (100\%) (Mulugeta et al. 2011; Afia et al., 2012; Goplakrishnan et al., 2012). Regarding the labeling score of dispensed drugs, the majority of dispensed drug have a labeling score of 4 in 410 (74 $\%$ ) and 5 of 187 (33.76\%) of the total dispensed drugs. The mean labeling score in the health center was 4.41 out of 7 and represents $63.00 \%$ of the total scores. The frequency of administration was recalled in over $79.06 \%$ of dispensed drugs which is higher than research done in Addis Ababa (60\%) and Ghana (54\%) (MOH., 2003; Afia et al., 2012). The duration of the treatment was recalled in nearly $36.82 \%$ of dispensed drugs are lower than the study done in Botswana (44\%) and higher than that of Ghana (6\%) (Bonnstra et al., 2003; Afia et al., 2012). This value is very low and most of the prescribed drugs were chemotherapeutic $(49.93 \%)$ out of which most were antibiotics so poor knowledge on duration of treatment may result in antibiotic resistance and should be improved. Patient knowledge score was calculated for each of the four attributes and the mean patient knowledge score was found to be 2.46 out of 4 attributes which is $(61.46 \%)$ of the total score. This value is lower than patient knowledge score found in primary health care in Botswana (2.5\%) (Bonnstra et al., 2003).

In the present study the educational level of respondents determined the patient knowledge on dispensed drugs ( $\mathrm{p}$-value $=0$. 000). In addition to educational status, age has also strong association on patient knowledge of dispensed drugs (p-value < 0.05). Whereas sex has no association with patient knowledge on dose, frequency and duration $(\mathrm{p}$-value $=0.423,0.630,0.115$ ) respectively. The average dispensing time obtained in this study was 152 seconds, which is lower than the study done in Niger (204 second) (Guyon et al., 1994; Mallet et al., 2001). But this value is greater than other studies done in Yugoslavian (20.5 to 48.2 seconds), Jordan (28.8 +/- 23.7 seconds), Tanzania (average of 84seconds), Southwest Ethiopia (73.8 to75 seconds), Bangladesh (23 seconds) and India (131.4 seconds) (Jankovic et al., 2001; Otoom et al., 2002; Nismbase., 2006; Mulugeta et al. 2011; Goplakrishnan et al., 2012). This outcome has an effect on patient satisfaction and enablement since dispensing time also includes dispensing counseling time, at which time the pharmacists counsel the patient. It is regarded to be short to allow optimal information to be given on medications and for answering the questions from patients. This value is still not enough to achieve high mean patient knowledge score. 
Table 9: Dispensing time at Adulala Health Center Outpatient Pharmacy from January 23- February 7, 2014

\begin{tabular}{|c|c|}
\hline Dispensing time (seconds) & Number of patients \\
\hline 25 & 1 \\
\hline 30 & 4 \\
\hline 32 & 1 \\
\hline 42 & 1 \\
\hline 45 & 1 \\
\hline 50 & 1 \\
\hline 56 & 1 \\
\hline 57 & 1 \\
\hline 60 & 13 \\
\hline 70 & 13 \\
\hline 80 & 11 \\
\hline 90 & 40 \\
\hline 102 & 1 \\
\hline 110 & 2 \\
\hline 117 & 3 \\
\hline 118 & 3 \\
\hline 120 & 43 \\
\hline 130 & 10 \\
\hline 133 & 4 \\
\hline 134 & 1 \\
\hline 140 & 16 \\
\hline 144 & 4 \\
\hline 150 & 33 \\
\hline 170 & 2 \\
\hline 180 & 20 \\
\hline 190 & 13 \\
\hline 193 & 2 \\
\hline 195 & 5 \\
\hline 198 & 2 \\
\hline 200 & 5 \\
\hline 201 & 3 \\
\hline 210 & 4 \\
\hline 220 & 1 \\
\hline 230 & 2 \\
\hline 240 & 3 \\
\hline 246 & 5 \\
\hline 250 & 1 \\
\hline 260 & 4 \\
\hline 270 & 6 \\
\hline 300 & 4 \\
\hline 310 & 1 \\
\hline 316 & 2 \\
\hline 330 & 2 \\
\hline 340 & 1 \\
\hline 381 & 2 \\
\hline 390 & 2 \\
\hline 410 & 1 \\
\hline 420 & 1 \\
\hline 45904 & 302 \\
\hline
\end{tabular}

\section{CONCLUSION}

The study showed that dispensed medications had poor labeling. Adequate patient knowledge score was not found. Educational level and patient age have a strong association with patient knowledge on dispensed drug whereas sex has no association with patient knowledge. Dispensing time was short when compared to WHO guidelines. Not all prescribed medications are dispensed. Dispenser should have a special concern for the elderly and low level educational status patients. The facilities should also provide dispensers at a pharmacy with marker for easy labeling in order to improve patient knowledge on their dispensed drug. Values for percentages of drugs actually dispensed are less, labeling of drugs and patient knowledge of the drug dispensed should be as high as possible.

Furthermore, Interventional study aimed at improving the quality of dispensing should be carried out using both labeling and knowledge scores. The dispensing time needs to be improved in order to allow patient ask questions what is not clear about their medication for improving rational drug use.

\section{ACKNOWLEDGMENTS}

The authors would like to thank all staff members of the Adulala Health Center Outpatient Pharmacy, Adulala, East Shoa, Ethiopia for their cooperation during data collection.

\section{REFERENCE}

Afia F. MARFO, Frances T. OwusuDaaku, Evelyn Kyerewaa-Akromah. 2012. Patient knowledge of medicines dispensed from Ghanaian community pharmacies. p3-5.

Bonnstra E. lindbaecm, Ngome E, Tshkudu d Fugeni P. Labeling and patient knowledge of dispensed drugs as quality indicators in primary care in Botswana. Quli Saf Health care. 2003; 12:168-175.

Cheraghali AM, Nikfar S, Behmanesh Y, Rahimi V, Habibipour F, Tirdad R, Asadi A, Baherama A. Evaluation of availability, accessibility and prescribing patterns of medicines in the Islamic Republic of Iran. Eastern Mediterranean Health Journal. 2004; 10 (3): 406-415.

Desta Z, Abula J, Beyene L, Fantahun M, Yohannis AG and Ayelews. Assessment of Rational drug use and prescribing in primary health care facilities in North West Ethiopia. East Afremed J. 2006; 44.

Federal Democratic Republic of Ethiopia Ministry of Health. Assessment of pharmaceutical sector in Ethiopia, 2003; 24-28

Gopalakrishnan S, Ajitha K, Ganeshkumar. P,Selvaraj. I, Logaraj. M. 2012. Assessment of patient care and health facility indicators among urban and rural private practitioners in Kancheepuram district of Tamil Nadu, India. p. 3-4.

Guyon AB, Barman A, Ahmed JU, Ahmed AU, Alam MS. A baseline Survey on use of drugs at the primary health care level in Bangladesh. Bull World health organization. 1994; 72(2): 265-11

Jankovic SM, Maksimovic MR, Vasanavoic A, Kostic IR, Kovacevic ZN, a1;Service Quality in Public and Private Pharmacies in the City of Kragujevac, Yugoslavian. Croatian Medical Journal. 2001; 42(1):88-91

Kralsce G, Bohert M, Benzler J, HeinmullerkabaI, Sava dogo M, Sinon and diesteld H. Rationally of drug prescription in rural health center in BurcinaFaso. Health policy and planning. 1999; 14 (3): 291-298

Mallet HP, Njikam A and scouflaire SM. Evaluation of prescription practice and of the ration use of medicine in Niger Sante. 2001; 11(3): 185-96.

Manual for good dispensing practice, DACA. Feb 2007.

Mulugeta $\mathrm{T}$ Angamo, Nasir $\mathrm{T}$ Wabe and N. J. Raju. Assessment of Patterns of Drug use by using World Health Organization's Prescribing, Patient Care and Health facility indicators 
in Selected Health Facilities in Southwest Ethiopia. Journal of Applied Pharmaceutical Science 2011; 1 (7): 62-66.

Nismbase. Assessing prescribing and patient care indicators for children under five years old with malaria and other disease conditions in public primary health care facility. South East Asian. TROPMED public health. 2006; 37 (1): 200-14

Otoom, batiena A, Hadid H, Hasen M, and AL-Sadic. Evaluation of drug use in Jordan using WHO patient care health care indicator. East Mediterr health J. Jul-sep 2002; 8(4-5): 544-9

Remington. 2005. The science and practice of pharmacy, $21^{\text {th }}$ Edition, New Delhi: Wolters Kluwer, 2033-35.

\section{How to cite this article:}

Bikila Midaksa, Fanta Gashe, Messay Wolde-Mariam Anshebo, Raghavendra Yarlagadda. Labeling and Patient Knowledge of Dispensed Drugs as Patient Care Indicators in Adulala Health Center Outpatient Pharmacy, Adulala, Ethiopia. J App Pharm Sci, 2015; 5 (09): 045-051. 